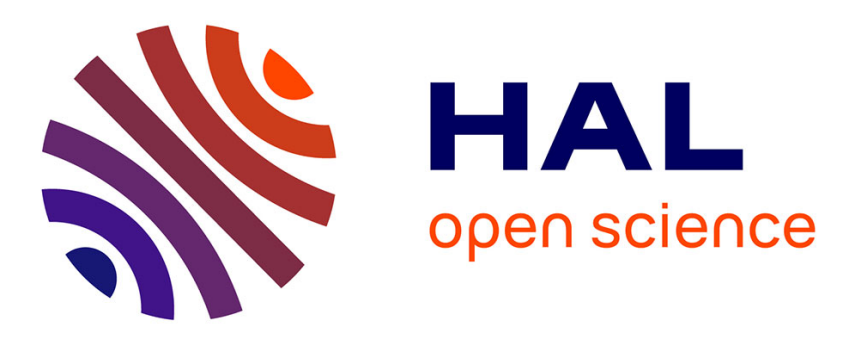

\title{
Design and modelling a mini-system with Piezoelectric actuation.
}

\author{
Simona Noveanu, Vencel Csibi, Ioan Alexandru Ivan, Dan Mandru
}

\section{To cite this version:}

Simona Noveanu, Vencel Csibi, Ioan Alexandru Ivan, Dan Mandru. Design and modelling a mini-system with Piezoelectric actuation.. 3rd European Conference on Mechanism Science, EUCOMES'10., Sep 2010, Cluj-Napoca, Romania. pp.1-8. hal-00632322

\section{HAL Id: hal-00632322 \\ https://hal.science/hal-00632322}

Submitted on 14 Oct 2011

HAL is a multi-disciplinary open access archive for the deposit and dissemination of scientific research documents, whether they are published or not. The documents may come from teaching and research institutions in France or abroad, or from public or private research centers.
L'archive ouverte pluridisciplinaire $\mathbf{H A L}$, est destinée au dépôt et à la diffusion de documents scientifiques de niveau recherche, publiés ou non, émanant des établissements d'enseignement et de recherche français ou étrangers, des laboratoires publics ou privés. 


\title{
Design and Modelling a Mini-System with Piezoelectric Actuation
}

\author{
S. Noveanu ${ }^{1}$, V.I. Csibi ${ }^{1}$, A. I. Ivan ${ }^{2}$, D. Mândru ${ }^{1}$ \\ ${ }^{I}$ Technical University of Cluj-Napoca, Romania, e-mail: \\ Simona.Noveanu@mmfm.utcluj.ro, csibiven@yahoo.com \\ Dan.Mandru@mmfm.utcluj.ro, \\ ${ }^{2}$ FEMTO-ST Institute, AS2M Department,France,e-mail: alex.ivan@femto-st.fr
}

\begin{abstract}
In this paper a new mini-system with piezoelectric actuation is presented. The piezoelectric actuation principle it is described and also an original mini-system is designed and analyzed. An experimental prototype of the compliant mini-mechanism is developed, in compact design, which amplifies the input displacement, with facile connection with the piezoelectric actuator. The piezoelectric actuator is commanded with different frequencies impulse signals.
\end{abstract}

Key words: Mini-system, compliant mechanism, piezoelectric actuator.

\section{Introduction}

The field of micromechanical devices is extremely broad. It encompasses all of the traditional sciences and engineering disciplines, only on a smaller scale. A distinctive feature of micro-electro-mechanical systems technology is miniaturization.

Mini-systems are diverse and complex and the trends indicate that it is appropriate to configure small-scale systems somewhat differently from those which we are familiar with. Simply downsizing from dimensions is not possible because of the scaling effect. This is due to the fact that the types of forces that are dominant in miniaturized devices are different from those that are dominant in macro-scale devices. For large-scale systems, inertial effects have a greater influence while surface effects influence smaller-scale systems. Being small, micro-systems are able to produce small forces only, $[2,7]$. In particular, there are used materials with special properties.

The size of a system and the physical parameters will be modified with a scale factor $\mathrm{S}$. When the scale size changes, all the dimensions of the object change by exactly the same amount $\mathrm{S}$ such that 1 : $\mathrm{S}$. This scale factor $\mathrm{S}$ can be used to describe how physical phenomena change. Knowing how a physical phenomenon 
scales, whether it scales as $\mathrm{S}^{1}$ or $\mathrm{S}^{2}$ or $\mathrm{S}^{3}$, or $\mathrm{S}^{4}$ or some other powers of $\mathrm{S}$, guides our understanding of how to design small mechanical systems [3].

Miniaturization of the mechanical structure alone is insufficient so that many devices may work together, so microelectronics needs to be incorporated in the system.

The reduced dimensions imply different manufacturing technologies, measuring and control techniques and specific actuation methods based on new types of actuators. Their actuation effect is achievable through three different means: fields interaction, mechanical interaction and induced limited strain. The actuators in the last category include elements made of so called intelligent or smart materials: piezoelectric and magnetostrictive materials, electro/magnetorheological fluids, electroactive polymers, shape memory alloys, [8].

\section{The structure of the mini-system}

The researched mini-system contains a mechanical part, represented by a compliant monoblock-type minigripper which is actuated by a piezo actuator.

In order to command and control the mini-system with DSpace data acquisition board, it is made a Simulink model that generates the command signals using the Signal generator blocks. The signals type can be: step, sinusoidal, ramp, impulse, a.s.o. Viewer in real-time behaviour of the system will be through the Control Desk application.

The proposed mini-system includes the following modules [9] (Fig. 1):

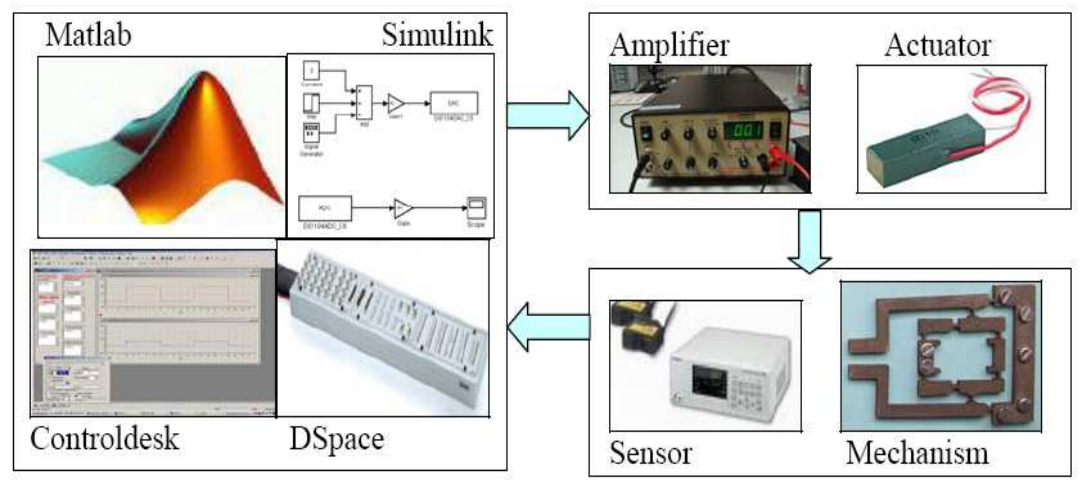

Fig. 1 The modules of the mini-system

The control is achieved in closed loop, with a reaction by position; it is necessary to measure the actuators displacements using suitable position sensors; the control of supply voltage of actuators is such that can obtain the exact position required by the mechanism action. 


\subsection{Piezoelectric actuators}

Regarding the piezoelectric materials (PZT) a tensile mechanical stress is induced that elongates and contracts the material due to the inverse piezoelectric effect, when they are placed in an alternative electric field. In order to amplify the actuators stroke, the stack and bimorph configurations are frequently used [13].

This "induced strain" or change in length occurs as electrical dipoles in the material rotate to align with an orientation that more closely aligns with the direction of the applied electric field. The change in length is generally proportional to the field strength as applied via the device actuation voltage [7]. A typical value for length change might be 0.1 percent of the total material length in the direction of the applied field. Application of an external field $\mathrm{E}_{\mathrm{m}}$ ( $\mathrm{m}$ stands for motor) in opposition to the poling field $\mathrm{E}_{\mathrm{p}}$ will generate an expansion of the piezoelectric sample by a mechanical deformation $\Delta \mathrm{u}$ (Fig. 2).

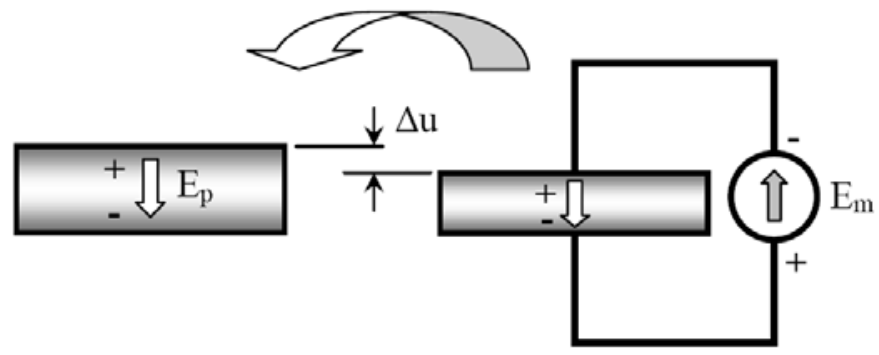

Fig. 2 Piezoelectric actuation through the reversed piezoelectric effect

Driving a piezoelectric actuator requires sourcing sufficient current from the driver to produce the desired electrical field or voltage level in the PZT stack. Because PZT stacks have relatively high capacitance, only a small amount of the energy delivered by the driver is used to move the load. The majority of the current applied is in the form of reactive power. Thus, the driving electronics must be able to move a relatively large amount of charge in and out of the PZT stack. This is slightly analogous to a four-quadrant drive for a DC motor with the added complication that the load is capacitive rather than resistive. Shortly, the drive electronics for a piezoelectric actuator are specialized for driving capacitive loads [13].

\subsection{Mini-mechanisms}

Conventional joints cannot be easily miniaturized, but using compliant mechanisms this problem can be solved. Compliant mechanisms can be miniaturized for use in simple microstructures, actuators and sensors. The monolithic construction also simplifies production, enabling low-cost fabrication, [9]. 
The compliant mechanisms are different from the traditional rigid body mechanisms in the sense that the last ones are rigid links connected by movable joints. They are used to transfer or transform energy and motions across themselves as desired by the users. The compliant mechanism does the same work except that their usability is also dependent on flexibility of some members. Compliant mechanisms have a smaller number of movable joints materialized as rotation joints. The result is the reduced wear and reduced need for lubrication. They also result in the reduction of noise and vibration due to reduced number of components and friction movements. Backlash reduction due to a decreased number of joints increases the mechanism precision [6].

Several approaches have previously been or are currently being taken to the design of small-scale precision mini/microgrippers $[1,4,5,10,11]$ : reducing the size of macro-gripping devices; using physical phenomena; the cantilever approach; the tweezers approach; distributed actuators; linkage-free actuators; using adhesion forces. The characteristics of an ideal multipurpose minigripper are: ability to manipulate micro-objects with various sizes and shapes, ability to work in various environments (in clean rooms, in liquids, etc.), ability to apply high forces, high accuracy, low response time, isolation between the control signals and the working area, simplicity of fabrication. Are characterized by a small opening span, a saw-like tip in order to reduce adhesion forces and are equipped with position and force sensors to provide quantitative information during grasping.

The mini and micro compliant mechanisms are fabricated by exploiting different technologies (Laser Micromachining, Electro Discharge Machining, LIGA, Stereo Lithography, precision machining).

\section{Modelling and simulation of the mini-system}

The developed mini-system contains the modules presented in figure 1: a minigripper designed as a device with flexible joints, actuated by a stack piezoactuator, an amplifier for the actuator, a displacement sensor and command and control modules.

The piezoelectric actuator used, is stack type, [12] and it has a maximum stroke of $15 \mu \mathrm{m}$, and overall dimensions are $18 \times 6.5 \times 6.5 \mathrm{~mm}$.

The analytical equations for displacements piezoelectric actuator [9] are:

$$
\Delta L=\mathrm{E} \cdot \mathrm{d}_{\mathrm{ij}} \cdot L_{0}+\frac{F}{c_{T}}
$$

where $\mathrm{E}$ is electric field; $\mathrm{d}_{\mathrm{ij}}$ - piezoelectric coupling coefficient; $\mathrm{L}_{0}$ - actuator length; $\mathrm{F}$ - axial force; $\mathrm{c}_{\mathrm{T}}$ - rigidity

$$
\begin{aligned}
& \Delta L=\Delta L_{0}+\frac{F}{c_{T}} \\
& \Delta L=(q U-F) / c_{T}
\end{aligned}
$$


where $\mathrm{q}$ is the factor for force and $\mathrm{U}$ is voltage

$$
\begin{aligned}
& \Delta L_{0}=\frac{F_{0}}{c_{T}} \\
& F_{0}=q U_{\text {max }}
\end{aligned}
$$

The time for response is:

$$
t_{r}=\frac{1}{2 f_{r}}
$$

where $f_{r}$ is the resonant frequency.

To compensate position change, one must drive the piezoelectric actuator to a slightly different voltage in the return movement to get back to the same starting position. The value of the stroke hysteresis is a percentage of the entire commanded stroke.

The overall dimensions of the mini-gripper in the structure of the studied minisystem are $54 \mathrm{~mm} \times 35 \mathrm{~mm} \times 2.21 \mathrm{~mm}$, [9]. The task for design is to find the geometry, with relevant dimensions in order to satisfy desired characteristics under specified constraints. These are: the range of motion for fingers, maximal external dimensions, available driving force and displacement and characteristics of material.

The solid model (Fig. 3a) and FEM analysis are realized in the linear domain, using Solid Works and ANSYS software. The meshed body is presented in the figure $3 b$.

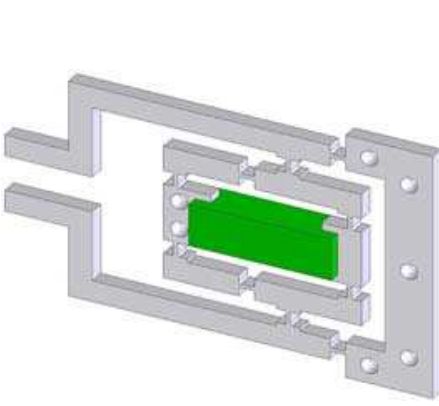

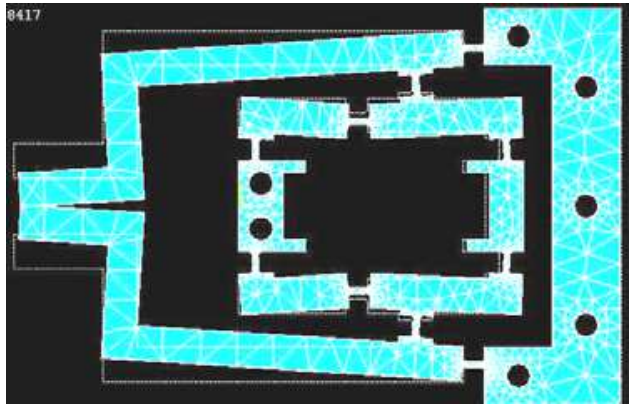

Fig. 3 The solid model and mesh realized for FEM analysis

The study was performed for the following applied input voltage: $0 \mathrm{~V} \div 120 \mathrm{~V}$ and the material used for analyze of the mini-gripper is alloy steel with: $\mathrm{E}=$ $2.1 \times 10^{5} \mathrm{~N} / \mathrm{mm}^{2}$, Poisson's Coefficient $=0.31$.

One functioning characteristic of the compliant minigripper is so-called mechanical advantage (m. a.), which is the output-to-input amplification (or deamplification) ratio $[6,7]$. The mechanical advantage determined through the FEM analysis for the studied mini-gripper is 6.50 . 


\section{Experimental results}

Our experimental study was focussed on the time response for different input signals.

In the next figure is presented a constructive variant of a compliant minigripper in the structure of the studied mini-system (Fig.4):

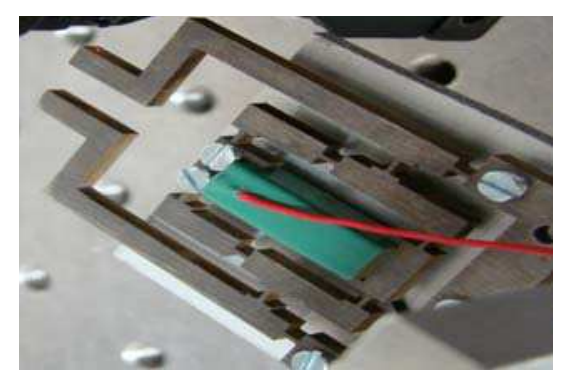

Fig. 4 The developed mini-gripper

For data acquisition at the piezoelectric actuator and compliant mini-gripper, we realized the command scheme in Simulink (Fig. 5a).and the interface using ControlDesk application (Fig. 5b).

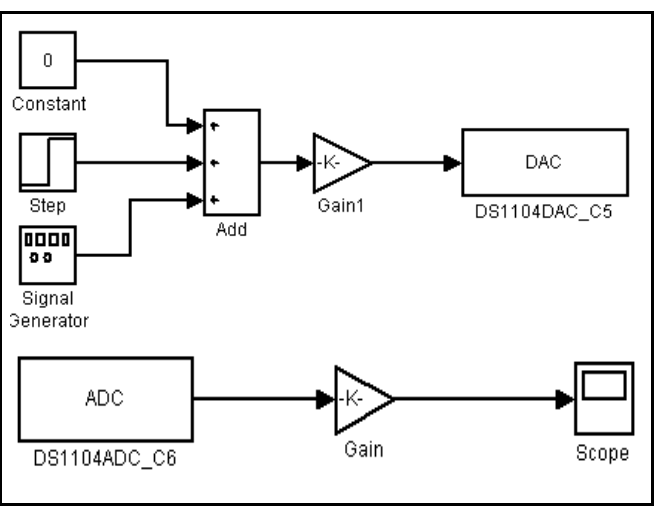

a

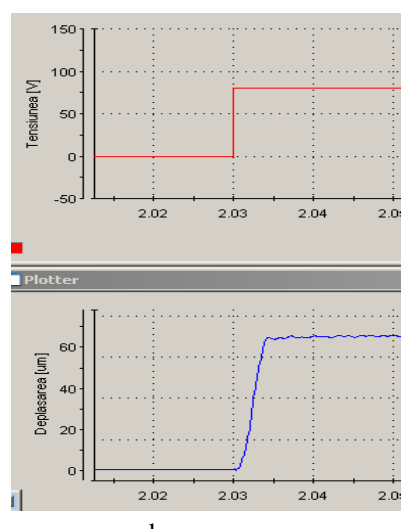

$\mathrm{b}$

Fig. 5 The command scheme in Simulink (a) and ControlDesk application (b)

The structure of the test bench for measurements contains a Laser displacement sensor LC-2420 with resolution $0.01 \mu \mathrm{m}$ and response time $100 \mu \mathrm{s}$.

The stack piezoelectric actuators - AE0505D18 have following characteristics: maximum drive voltage 150 volts; operating temperature: $0^{\circ} \mathrm{C} \div 45^{\circ} \mathrm{C}$; capacitance: $1600 \mathrm{nF} \div 320 \mathrm{nF}$; clamping force: $853 \mathrm{~N}$; resonant frequency: $261 \mathrm{KHz}$; Young's modulus: $4.4 \times 10^{10} \mathrm{~N} / \mathrm{m}^{2}$; recommended preload less than $100 \mathrm{~N}$. 
The study was performed for the following inputs: voltage is $150 \mathrm{~V}$ and impulse signal: $0.1 \mathrm{~Hz} \div 100 \mathrm{~Hz}$ (Fig. 6).

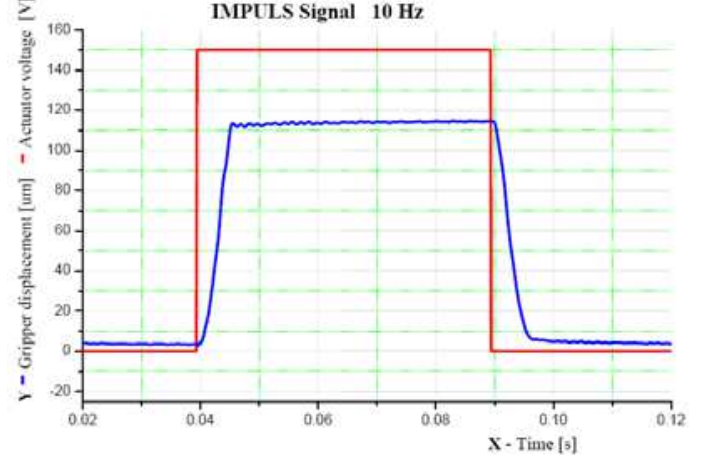

a

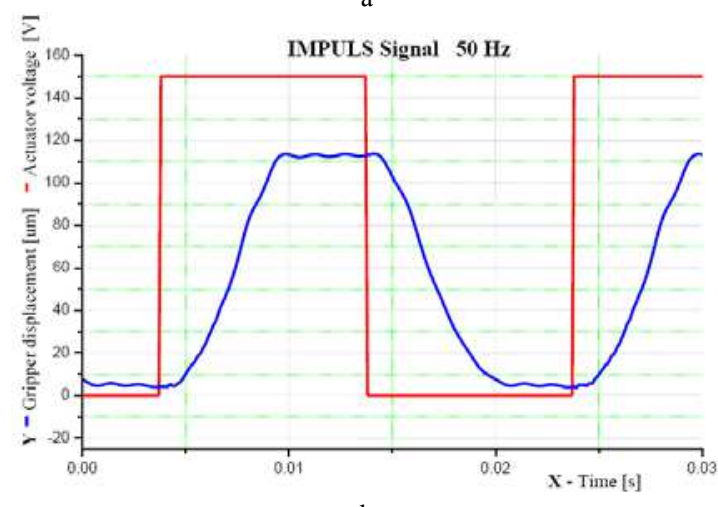

b

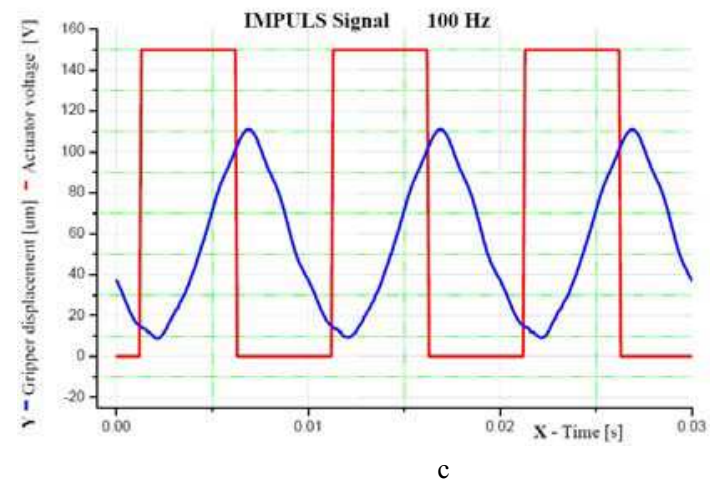

Fig. 6 The experimental results for impulse signal and different frequencies

Figures $6 \mathrm{a}, \mathrm{b}$ show that for a proper functioning, the mini-system has to be actuated with a frequency below $50 \mathrm{~Hz}$. Figure $6 \mathrm{c}$ shows that the mini-system oscillates for a frequency equal with $100 \mathrm{~Hz}$. 


\section{Conclusions}

The paper points out some specific problems in functioning of mini-mechanical systems built on compliant mechanisms. In order to test the performance of the minigripper with piezo actuators an experimental test bench was developed. The mini-system starts to oscillate for frequency values higher than $50 \mathrm{~Hz}$. In conclusion, for a proper functioning, the system has to be actuated with a frequency below that value. The control is achieved in closed loop, with a reaction by position; it is necessary to measure the actuators displacements using suitable position sensors; the control of supply voltage of actuators is such that can obtain the exact position required by the mechanism action.

The mini-system can be successfully applied to the fields that need high precision in small workspace, such as: optics, precision machine tools and mini component fabrication.

In the future the aim of our work will be to down scale the mini-system analyzed in this paper.

Acknowledgments The research work reported here was made possible by PNII - IDEI Project, ID 221: Modelling, Simulation and Control of the Compliant Micro mechanisms and PNII - ID 1076 Development of a Modular Family of Linear and Rotary Actuators Based on Shape Memory Alloys.

\section{References}

1. Bassan, H., et.al: Control of a rigid manipulator mounted on a compliant base, Robotica vol 23, pp. 197-206, Cambridge University Press,(2005)

2. Fatikow, S.: Microsystems Technology and Microrobotics, (Series: The Mechanical Engineering Handbook). Springer (1997)

3. Gad-el-Hak, M.: The MEMS handbook, (Series: The Mechanical Engineering Handbook). CRC Press LLC (2001)

4. Havlik, S.: Analysis and modeling flexible robotic (micro) mechanisms. In Proc. of the 11th World Congress in Mechanism and Machine Science, Tianjin, Vol. 3, pp.1390-1395, (2004)

5. Kota, S.: Design and Application of Compliant Mechanisms for Surgical Tools, Journal of Biomechanical Engineering, Vol. 127, pp.981-989 (2005)

6. Lobontiu, N.: Compliant Mechanisms: Design of Flexure Hinges, CRC Press LLC, (2002).

7. Lobontiu, N. and Garcia, E.: Mechanics of microelectromechanical systems, (Series: The Mechanical Engineering Handbook). Springer (2004)

8. Mândru, D. et al,: Actuating Systems in Precision Mechanics and Mechatronics. AlmaMater (2004)

9. Noveanu, S.: Contributions concerning the study of compliant mechanisms specific to mechatronic systems, Ph.D. Thesis, (2009)

10. Refaat M.H. and Meguid S.A.: Accurate modelling of compliant grippers using a new method, Robotica, Cambridge University Press, Vol. 16, pp. 219-225, (1998)

11. Voyles, R. M.., Hulst, S, Micro/macro force-servoed gripper for precision photonics assembly and analysis, Robotica, Cambridge University Press, volume 23, pp. 401-408, (2005)

12. http://www.thorlabs.com

13. http://www.dynamic-structures.com 